psychological difficulties within their own cultural framework improves, it is very difficult to expect a dramatic change in the existing system. In fact any such efforts will be quite futile.

RAMEEZ ZAFAR, Lincoln District Healthcare NHS Trust, Peter Hodgkinson Centre, County Hospital, Lincoln LN2 5QY

\section{Examination techniques}

Sir: We share the concerns of Dr Donnelly in his description of the problems that junior psychiatrists often have in passing the MRCPsych clinical examinations (Psychiatric Bulletin, May 1995, 19, 302-304). We believe that very good candidates sometimes fail more because of poor examination technique than a lack of knowledge or clinical skills. On the MCQ papers it is possible to score $74 \%$ of answers correctly yet because of negative marking' a net mark of only $48 \%$ may be achieved if every other response is wrong.

Other aspects of the exams illustrate the same point; having good levels of knowledge and clinical skills may not be enough to pass. The ability to present essays, SAQs, PMPs and the clinical case in an organised and professional manner is not one that comes naturally to everyone. These are skills that need to be practised and developed.

It is our experience, in teaching candidates in Yorkshire, that specific teaching of examination technique is sometimes overlooked by candidates and trainers alike. Within the setting of the Leeds Examination Techniques Course (which is run twice yearly) candidates are offered clear teaching in case presentation, and practise in each area of the written exam (Williams et al, 1995). The purpose of the course is not to teach facts about psychiatry (it is the responsibility of each candidate to learn these), but to encourage each candidate to present what they do know effectively. The skills required in the exam are also the skills of a good psychiatrist; to effectively gather, organise and integrate information in order to decide on appropriate treatment approaches.

Learning factual knowledge and clinical skills alone, although important, is not enough. We would encourage all trainees and trainers to be aware that candidates need to practise specific exam techniques as well, so that they can communicate these skills effectively.

Willams. C. J., Trigwel., P. \& Yeomans, J. D. I. (1995) Pass the MRCPsych Parts I and II (All the techniques you need). London: Baillière Tindall/WB Saunders.

Chris Williams, David Yeomans and Peter TRIGWELl, St James's University Hospital, Leeds LS9 7TF

\section{Mental Health Task Force Support Group}

Sir: Reading the briefing on the Mental Health Task Force Support Group by Wattis \& Thompson (Psychiatric Bulletin. April 1995, 19, 250-251), we are unsure as to how they have advanced the "cause of services for people with mental illness". One has the impression that there had been much consultation with 'user groups' and the publication of many documents - but to what effect, other than guidelines suggested elsewhere? Mention was made of the newsletter Grass Roots, supposedly circulated to notify people of the work of the Task Force, but it was unknown in the psychiatric hospital where we work.

The Task Force was set up to "help ensure the substantial completion of the transfer of services away from large old-style hospitals to a balanced range of comprehensive locallybased services" (Jenkins, 1994). However we suspect that this was a government quango set up to provide little more than a public relations exercise. We would be interested to hear of any tangible benefits of the Mental Health Task Force others have observed.

JENKINS, R. (1994) The Health of the Nation. recent government policy and legislation. Psychiatric Bulletin. 18. 324-327.

STEVEN REID and JOANNE TURNER, Springfield Hospital, 61 Glenburnie Road, London SW17 7DJ

\section{Interaction between staff of psychiatric intensive care units}

Sir: There is very little formal interaction between staff of psychiatric intensive care units (PICU), e.g. at College level. Unlike 